\title{
PEMBUATAN APLIKASI E-LEARNING PADA SMK SWASTA PARIWISATA IMELDA MEDAN
}

\author{
Hengki Tamando Sihotang \\ Teknik Informatika \\ STMIK Pelita Nusantara Medan, Jl Iskandar Muda No.1, Medan, Sumatera Utara, 20154, Indonesia \\ hengki_tamando@yahoo.com
}

\begin{abstract}
Abstrak
SMK Swasta Priwisata Imelda Medan adalah salah satu sekolah SMK swasta yang ada di kota Medan. Sistem pembelajaran di SMK Pariwisata Imelda Medan masih menggunakan sistem manual yang berarti proses belajar mengajar masih terikat oleh waktu mata pelajaran yang tersedia dan harus bertatap muka dengan pengajar mata pelajaran. Materi mata pelajaran di SMK Swasta Pariwisata Imelda Medan cukup sulit sehingga Pengajar dan siswa memerlukan waktu yang lama dalam mengajar dan belajar. untuk memdukung sistem pembelajaran yang efektif pada SMK Pariwisata Imelda Medan perlu dibuat suatu sistem pembelajaran yang berbasis e-lektronik yaitu e-learning. penulis menggunakan bahasa php, mysql, dreamweaver dan Xampp Control Pane Version 2.5.8, untuk memberikan solusi dalam proses belajar dan mengajar di SMK Swasta Pariwisata Imelda Medan agar memudahkan siswa dan pengajar dalam proses belajar mengajar tanpa batas waktu pelajaran yang disediakan sekolah.
\end{abstract}

Kata Kunci : E-Learning, PHP, MySQL, Dreamweaver 8 dan Xampp Control Pane Versi 2.5.8.

\begin{abstract}
SMK Swasta Priwisata Imelda Medan is one of the private vocational schools in Medan. Learning system at SMK Swasta Priwisata Imelda Medan still use manual system which means the teaching and learning process is still bound by the time the subjects are available and must meet face-to-face with subject teachers. Subject material in the SMK Swasta Pariwisata Imelda Medan is quite difficult so that teachers and students need a long time in teaching and learning. to support an effective learning system at SMK Swasta Pariwisata Imelda Medan needs to be made an e-learning based learning system that is e-learning. the author uses the php language, mysql, dreamweaver and Xampp Control Panel Version 2.5.8, to provide solutions in the process of learning and teaching at SMK Swasta Pariwisata Imelda Medan in order to facilitate students and teachers in teaching and learning without the time limit provided by the school.
\end{abstract}

Keywords: E-Learning, PHP, MySQL, Dreamweaver 8 and Xampp Control Pane Version 2.5.8.

\section{PENDAHULUAN}

Saat ini perubahan dan penyempurnaan kurikulum pendidikan terus dilaksanakan. Perubahan kurikulum tersebut dituntut mengikuti perkembangan teknologi saat ini.

Dengan demikian, diperlukan pembelajaran berbasis teknologi yang dapat meningkatkan kualitas bidang pendidikan, salah satunya adalah berbasis web. Proses belajar mengajar berbasis web dapat membantu siswa dalam mendapatkan informasi dan dapat membantu sekolah dalam mempromosikan kegiatan sekolah tersebut. Web dapat membuat sebuah aplikasi yang disebut dengan e-learning. E-learning merupakan suatu sistem pembelajaran yang efektif dan dapat digunakan dimana saja dan kapan saja tanpa terikat waktu dan tanpa harus bertatap muka. $E$ learning berisi materi pelajaran yang disampaikan oleh pengajar kepada siswa dan siswa dapat mendownloadnya dengan format PDF dan Document, melihat teman satu kelas, melihat mata pelajaran dan mengerjakan tugas atau quis. Materi pelajaran dan tugas atau kuis yang ada di dalam sistem e-learning dapat disesuaikan dengan kelas yang diduduki.

SMK Swasta Pariwisata Imelda Medan adalah salah satu sekolah SMK swasta yang ada di kota Medan. SMK Swasta Pariwisata Imelda Medan masih belum memiliki akses berbasis web baik itu e-library, pendaftaran online, website sekolah bahkan sistem pembelajaran di sekolah tersebut masih manual yang berarti proses belajar 
mengajar masih terikat oleh waktu mata pelajaran yang tersedia dan harus bertatap muka dengan pengajar mata pelajaran.

Maka dari pada itu peneliti ingin membuat sistem pembelajaran SMK Swasta Imelda Medan yang manual menjadi sistem pembelajaran berbasis $e$-learning. Tujuan dan manfaatnya untuk Membangun sistem pembelajaran e-learning yang dapat diakses oleh siswa tanpa terikat dengan waktu dan tempat serta menambah motivasi siswa untuk belajar dan membaca

\section{TEORI}

\section{A. Aplikasi}

Program Aplikasi adalah program siap pakai. Aplikasi akan menggunakan sistem operasi (OS) komputer dan aplikasi yang lainnya yang mendukung [1].

\section{B. Web}

Web atau disebut website merupakan kumpulan halaman yang menampilkan informasi baik bersifat statis dan dinamis dimana masingmasing dihubungkan dengan jaringan-jaringan halaman (hyperlink) [1].

\section{E-Learning}

E-Learning adalah memanfaatkan teknologi informasi dan komunikasi (TIK) secara sistematis pada proses pembelajaran [2]. Dapat disimpulkan bahwa e-learning merupakan pembelajaran yang mengenai tentang materi pelajaran yang ada disekolah.

\section{D. $P H P$}

PHP atau disebut Hypertext Preprocessor adalah sebuah bahasa pemrograman web yang terintegrasi dengan $H T M L[3]$.

\section{E. $M y S Q L$}

Mysql adalah sebuah server database atau yang disebut DBMS (Database Management System) yang bersifat open source yang digunakan untuk membuat sebuah web[2].

\section{F. UML (Unifield Modeling Language)}

UML (Unifield Modeling Language) adalah sebuah standarisasi bahasa pemodelan yang menggunakan teknik pemrograman beriorientasi objek [2]. UML terdiri dari beberapa, antara lain : 1. Use Case Diagram
Use Case Diagram merupakan pemodelan untuk kelakuan (behavior) sistem informasi yang digunakan untuk mengetahui apa saja yang ada di dalam sistem informasi dan siapa saja yang berhak menggunakan fungsi-fungsi sistem informasi yang dibangun [2].

2. Class Diagram

Class diagram merupakan mengambarkan struktur sistem dari segi pendifisian kelaskelas untuk membangun sistem [4].

3. Activity Diagram

Activitiy diagram merupakan aktivitasaktivitas dari sebuah sistem yang dibuat [2].

\section{III.ANALISA DANPERANCANGAN}

A. Use Case Diagram

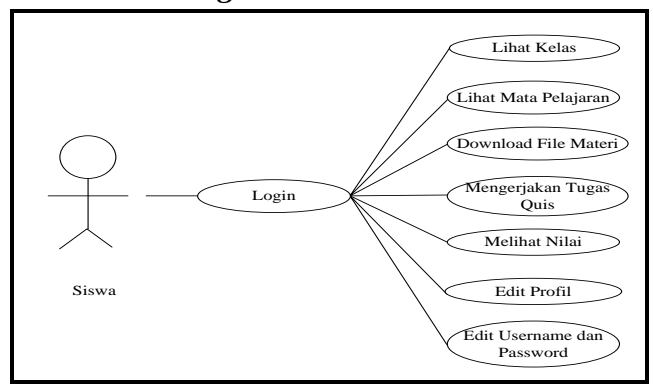

Gambar 1. Use Case Diagram Siswa

Di gambar tersebut Siswa harus login atau masuk terlebih dahulu agar dapat melihat kelas, mata pelajaran, materi, mengerjakan tugas/kuis dan melihat nilai quis yang telah di koreksi pengajar

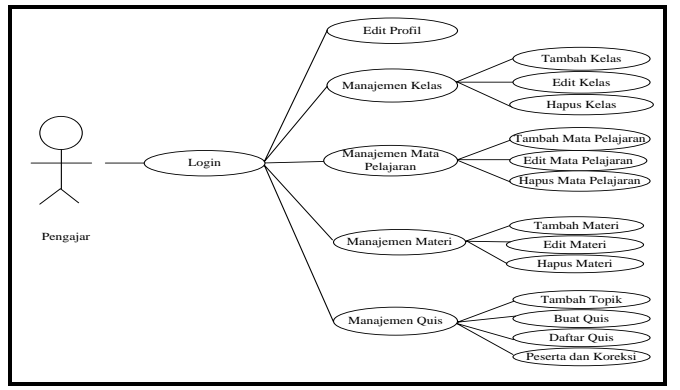

Gambar 2. Use Case Diagram Pengajar

Pengajar terlebih dahulu harus login dengan menggunakan user name dan password. Pengajar dapat manajemen mata pelajaran, kelas, materi pelajaran dan tugas/quis. 


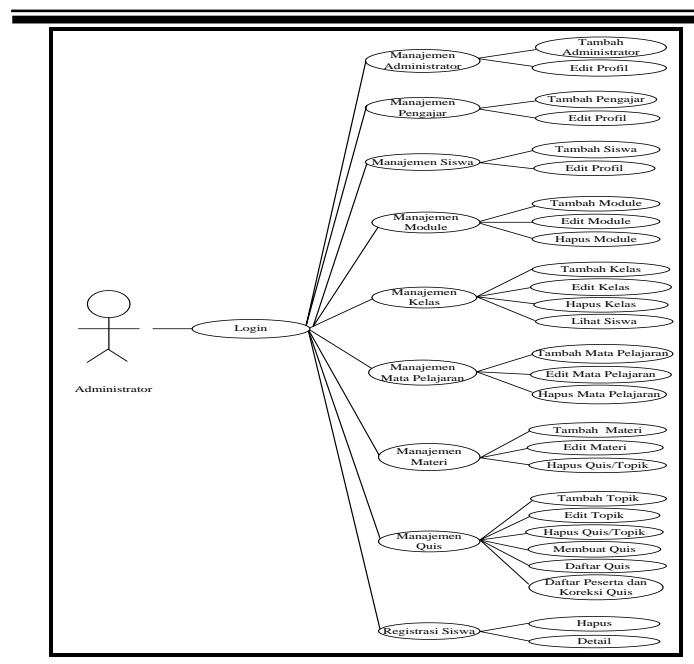

Gambar 3. Use Case Diagram Administrator

Administrator terlebih dahulu harus login dengan menggunakan user name dan password. Administrator dapat manajemen mata pelajaran, kelas, tugas/quis, siswa, pengajar, administrator, menerima registrasi siswa, dan materi.

\section{B. Activity Diagram}

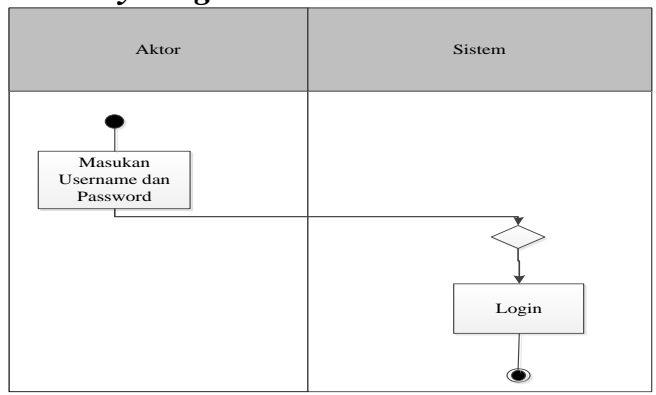

Gambar 4. activity diagram login

Siswa, pengajar dan administrator harus login atau masuk dulu agar dapat menggunakan $e$ learning.

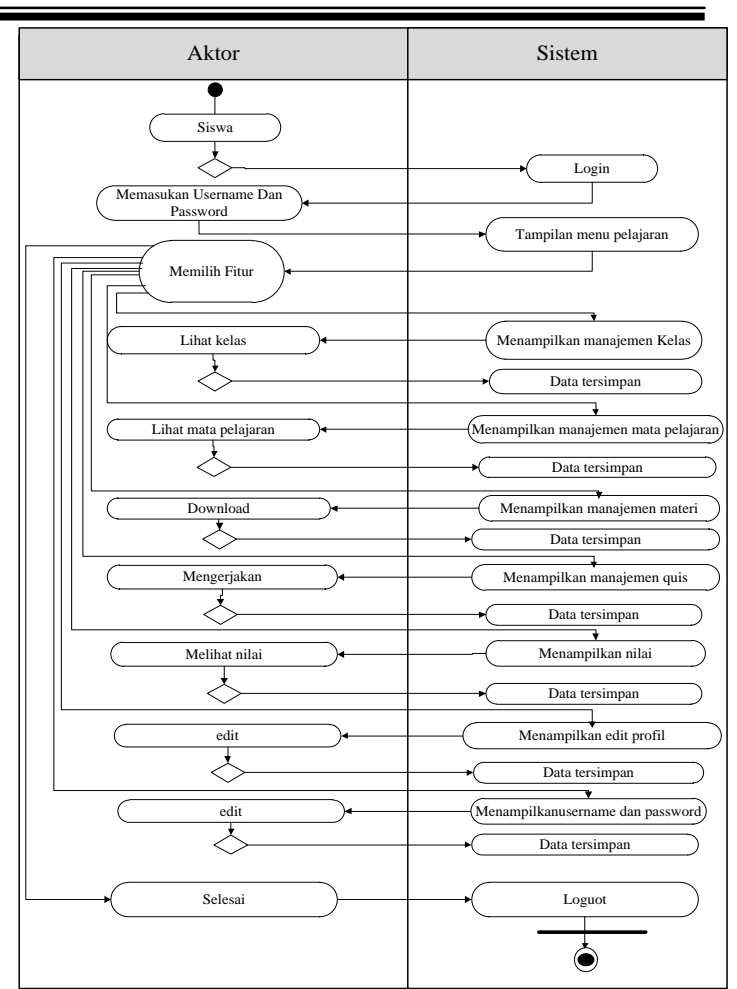

Gambar 5. Activity Diagram Siswa

Siswa dapat login kedalam e-learning dengan menggunakan nim sebagai username dan password. Akan muncul tampilan menu pelajaran. Kemudian siswa dapat memilih fitur-fitur yang ada di dalam sistem e-learning siswa. Siswa hanya dapat melihat kelas, mata pelajaran, mendownload materi, mengerjakan quis. melihat nilai quis yang telah di koreksi pengajar dan mengedit profil. Perubahan-perubahan yang dilakukan aktor disimpan kedalam sistem $e$ learning. setelah siswa selesai menggunakan $e$ learning, siswa harus login. 


\section{Class Diagram}

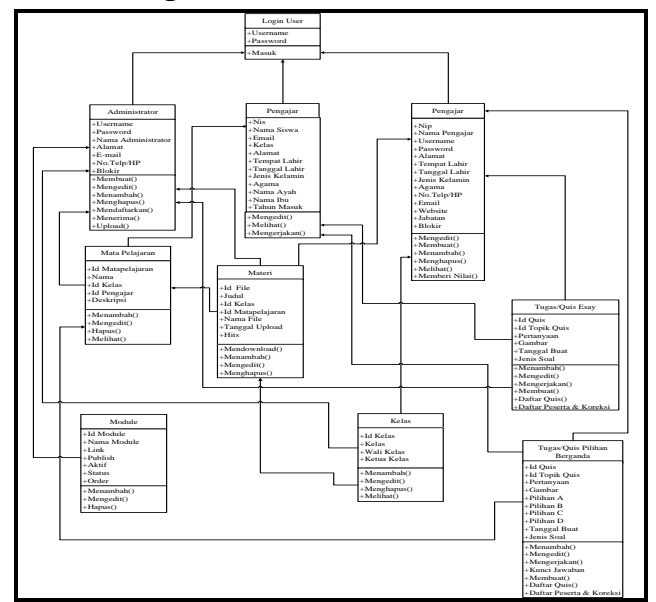

Gambar 6. Class Diagram E-learning

Class diagram menunjukkan beberapa kelaskelas yang di ambil dari use case diagram, yaitu :

1. Siswa, pengajar dan administrator terlebih dahulu harus login dengan menggunakan user name dan password.

2. Siswa, Pengajar dan Administrator mendaftar dengan menggunakan biodata.

3. Mata pelajaran yang terdapat id mata pelajaran, nama, id kelas, nim dan deskripsi.

4. Didalam kelas terdapat id kelas, kelas, wali kelas dan ketua kelas.

5. Didalam materi terdapat id file, judul, id kelas, id pelajaran,nama file, tanggal upload dan hits

6. Pengajar dan administrator dapat mengkoreksi atau memberi nilai. Didalam quis terbagi menjadi 2 bagian, yaitu :

a). Essay terdapat id quis, id topik quis, pertanyaan, gambar, tanggal buat, jenis soal.

b). Pilihan berganda terdapat id quis, id topik quis, pertanyaan, gambar, memilih jawaban dengan memilih A, B, C dan D kemudian sistem akan mengunci jawaban yang telah dipilih siswa, tanggal buat dan jenis soal.

\section{IV.HASIL DAN PEMBAHASAN}

A. Tahapan Implementasi Sistem

Berikut gambaran hasil sistem e-learning yang sudah selesai di bangun :

1. Sistem E-Learning Untuk Siswa

a). Halaman Login dan pendaftaran Siswa siswa harus login terlebih dahulu atau mendaftar seperti gambar berikut ini :

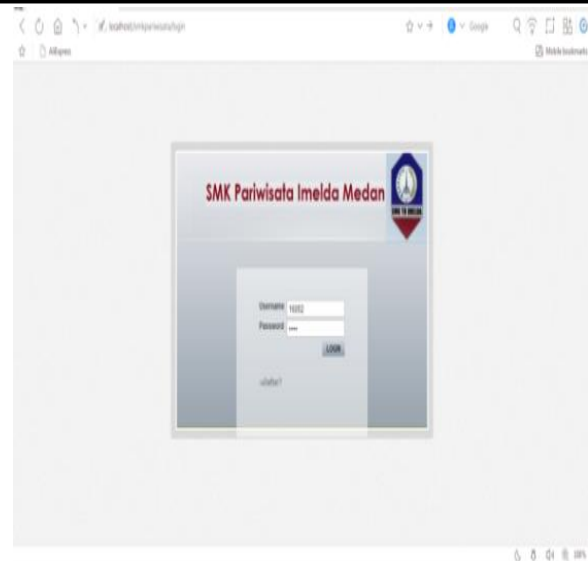

Gambar 7. Login Siswa

b). Beranda siswa

Setelah siswa berhasil login akan muncul tampilan beranda siswa dan didalam beranda terdapat fitur-fitur siswa seperti gambar dibawah ini :

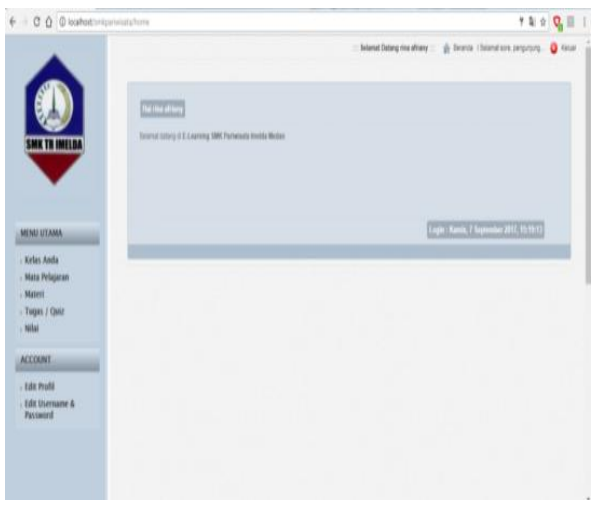

Gambar 8. Beranda Siswa

c). Halaman kelas

Setelah muncul beranda, pilih fitur kelas jika siswa ingin melihat teman sekelasnya seperti gambar dibawah ini :

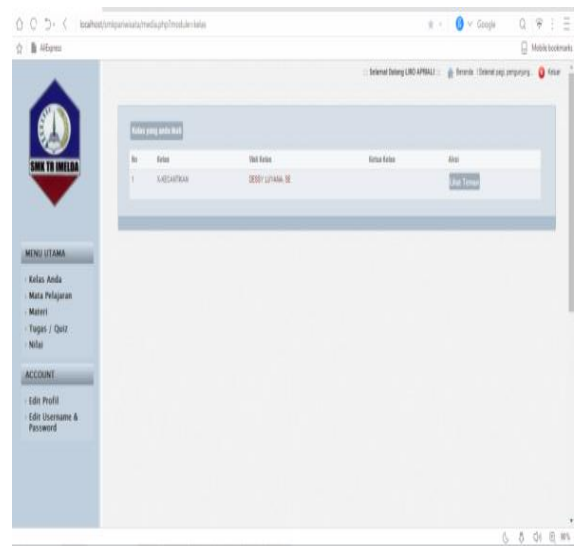

Gambar 9. Halaman Kelas 
d). Halamanan mata pelajaran

Pilih fitur mata pelajaran jika siswa ingin melihat mata pelajaran seperti gambar berikut ini :

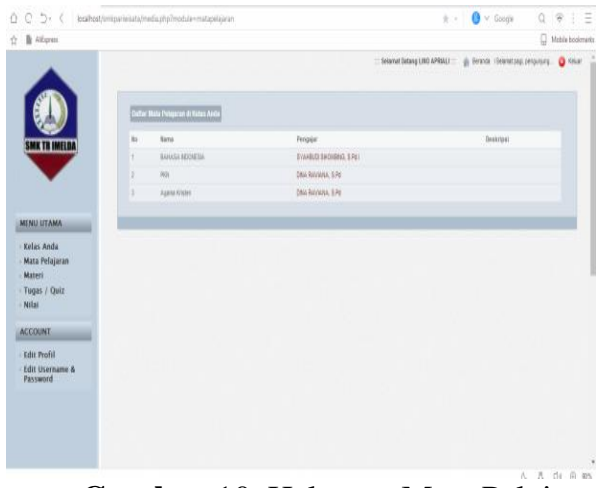

Gambar 10. Halaman Mata Pelajaran

e). Halaman materi

Pilih fitur materi jika siswa ingin melihat materi seperti gambar dibawah ini :

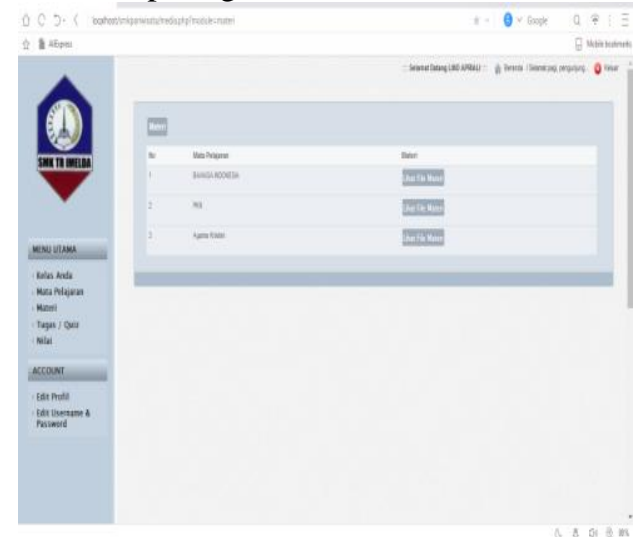

Gambar 11. Halaman Materi

f). Halaman tugas/quis

Pilih fitur tugas/quis jika siswa ingin mengerjakan quis seperti gambar dibawah ini :

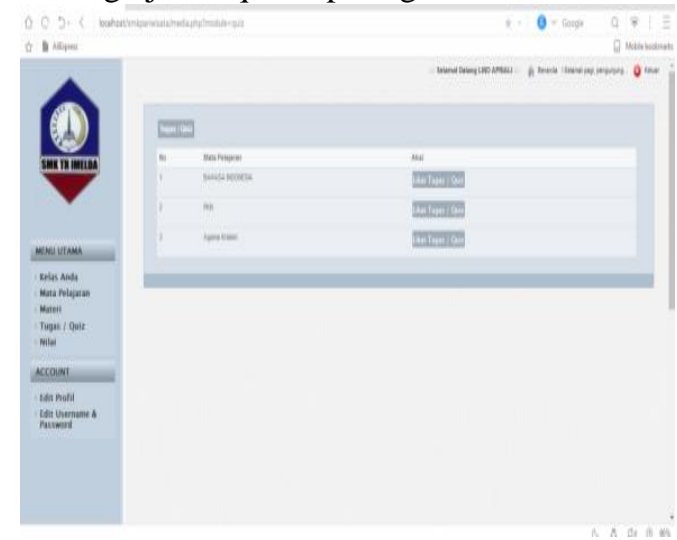

Gambar 12. Halaman Tugas/Quis g). Halaman nilai

Pilih fitur nilai jika siswa ingin melihat nilai. Seperti gambar berikut ini :

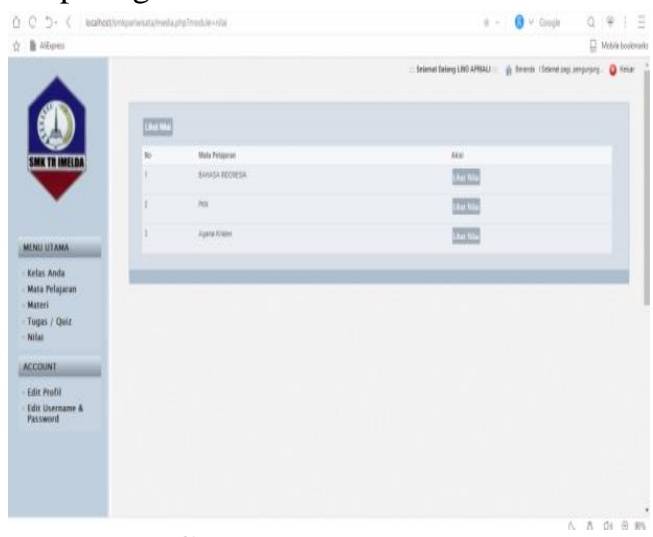

Gambar 13. Halaman Nilai

\section{B. Pembahasan}

Pembahasan merupakan bahasan tentang hasil sistem yang dibangun sudah berjalan dengan baik. Berikut dibawah ini merupakan tabel hasil pada sistem :

TABEL I

HASIL SISTEM E-LEARNING SISWA

\begin{tabular}{|c|c|c|c|c|}
\hline No & $\begin{array}{l}\text { Sistem } \\
\text { yang } \\
\text { Diuji }\end{array}$ & $\begin{array}{c}\text { Cara } \\
\text { pengujian }\end{array}$ & $\begin{array}{l}\text { Hasil Yang } \\
\text { Diharapkan }\end{array}$ & Hasil \\
\hline 1. & $\begin{array}{l}\text { Halaman } \\
\text { login }\end{array}$ & $\begin{array}{l}\text { Masukkan } \\
\text { username } \\
\text { dan } \\
\text { password }\end{array}$ & $\begin{array}{l}\text { Tampilan } \\
\text { pada halaman } \\
\text { login tidak } \\
\text { error }\end{array}$ & Baik \\
\hline 3. & $\begin{array}{l}\text { Halaman } \\
\text { kelas }\end{array}$ & $\begin{array}{l}\text { Pilih fitur } \\
\text { kelas }\end{array}$ & $\begin{array}{l}\text { Tampilan } \\
\text { pada halaman } \\
\text { kelas tidak } \\
\text { error }\end{array}$ & Baik \\
\hline 4. & $\begin{array}{l}\text { Halaman } \\
\text { mata } \\
\text { pelajaran }\end{array}$ & $\begin{array}{l}\text { Pilih fitur } \\
\text { mata } \\
\text { pelajaran }\end{array}$ & $\begin{array}{l}\text { Tampilan } \\
\text { pada halaman } \\
\text { mata } \\
\text { pelajaran } \\
\text { tidak error. }\end{array}$ & Baik \\
\hline 5. & $\begin{array}{l}\text { Halaman } \\
\text { materi }\end{array}$ & $\begin{array}{l}\text { Pilih fitur } \\
\text { materi }\end{array}$ & $\begin{array}{l}\text { Tampilan } \\
\text { pada halaman } \\
\text { materi dan } \\
\text { download } \\
\text { materi tidak } \\
\text { error. }\end{array}$ & Baik \\
\hline 6. & $\begin{array}{l}\text { Halaman } \\
\text { tugas/qui } \\
\mathrm{s}\end{array}$ & $\begin{array}{l}\text { Pilih fitur } \\
\text { tugas/quis }\end{array}$ & $\begin{array}{l}\text { Tampilan } \\
\text { pada halaman } \\
\text { tugas/quis } \\
\text { tidak error. }\end{array}$ & Baik \\
\hline 7. & $\begin{array}{l}\text { Halaman } \\
\text { nilai }\end{array}$ & $\begin{array}{l}\text { Pilih fitur } \\
\text { nilai }\end{array}$ & $\begin{array}{l}\text { Tampilan } \\
\text { pada halaman } \\
\text { nilai tidak } \\
\text { error. }\end{array}$ & Baik \\
\hline 8. & $\begin{array}{l}\text { Halaman } \\
\text { edit } \\
\text { Profil } \\
\end{array}$ & $\begin{array}{l}\text { Pilih fitur } \\
\text { edit Profil }\end{array}$ & \begin{tabular}{lr}
\multicolumn{2}{l}{ Tampilan } \\
pada halaman \\
edit $\quad$ Profil
\end{tabular} & Baik \\
\hline
\end{tabular}




\begin{tabular}{|c|c|c|c|c|}
\hline No & $\begin{array}{l}\text { Sistem } \\
\text { yang } \\
\text { Diuji }\end{array}$ & $\begin{array}{c}\text { Cara } \\
\text { pengujian }\end{array}$ & $\begin{array}{l}\text { Hasil Yang } \\
\text { Diharapkan }\end{array}$ & Hasil \\
\hline & & & tidak error & \\
\hline 9. & $\begin{array}{l}\text { Halaman } \\
\text { edit } \\
\text { username } \\
\& \\
\text { password }\end{array}$ & $\begin{array}{l}\text { Pilih fitur } \\
\text { edit } \\
\text { username } \\
\& \\
\text { password }\end{array}$ & $\begin{array}{l}\text { Tampilan } \\
\text { pada halaman } \\
\text { edit username } \\
\& \text { password } \\
\text { tidak error }\end{array}$ & Baik \\
\hline
\end{tabular}

\section{Kelemahan dan Kelebihan Sistem}

1. Kelemahan :

Kelemahan dari sistem e-learning yang

dibangun yaitu :

a. Sistem e-learning yang dibangun tidak bisa atau tidak dapat melakukan chat atau obrolan.

b. Sistem yang dibangun belum sampai tahap keamanan data.

c. Tampilan sistem e-learning hanya berbentuk sederhana tidak mengggunakan banyak animasi.

2. Kelebihan :

Kelebihan dari sistem e-learning yang dibangun yaitu :

a. Dapat membantu siswa dalam proses belajarnya.

b. Dapat membantu pengajar dalam proses mengajarnya.

c. Siswa dapat melihat teman sekelasnya.

d. Siswa dapat latihan dengan mengerjakan tugas/quis agar siswa dapat menggasa pikiranya.

e. Siswa dapat melihat materi pelajaran yang belum tersampaikan pengajar pada saat jam pelajaran dan mendownload materi.

f. Pengajar dapat menyampaaikan materi pelajaran yang belum tersampaikan pada saat jam pelajaran.

g. Pengajar dapat melihat pengetahuan siswa dari mengerjakan tugas/quis.

\section{KESIMPULAN}

Berikut Kesimpulan yang diambil berdasarkan hasil uraian dari bab I sampai dengan bab IV, yaitu :

1. Pembuatan sistem e-learning berdasarkan dari use case diagram, activity diagram, dan class diagram. Sistem yang dibangun mengunakan bahasa $p h p$ dan database mysql.

2. Dengan adanya Aplikasi e-learning dapat membantu siswa belajar tanpa terikat waktu mata pelajaran, mengisi waktu luangnya dengan belajar dan pengajar dapat mengajarkan siswanya tanpa terikat waktu mata pelajaran.

\section{REFERENSI}

[1]Eri Haeril Jana dan Tri Ginanjar Laksana, "Aplikasi E-Learning Berbasis Web Untuk Meningkatkan Motivasi Pembelajaran (Studi Kasus : SMA Negeri 1 Telaga Kab. Cirebon)", Jurnal Online ICT STMIK IKMI, 2012, Vol.1 No. 2

[2]Raedy Yosrinanto, Irawan Thamrin, S.T, M.T dan Gunawan, S.T., MOS " Aplikasi ELearning Berbasis Framework Codeigniter (Studi) Kasus : Jurusan Teknik Informatia Politeknik Negeri Bandung)", e-Proceeding of Applied Science. 2015, Vol.1 No.1

[3] Praptiningsih dan Bambang Eka Purnama, “ Pembuatan Engine E-Learning Pada Sekolah Menengah Pertama (SMP) Negeri 2 Kebonagung", IJNS - Indonesia Journal On Networking And Securlty, 2015, Vol4 No.1.

[4] Winda Aprianti dan Umi Maliha, "Sistem Informasi Kepadatan Penduduk Kelurahan Atau Desa Studi Kasus Pada Kecamatan BatiBati Kabupaten Tanah Laut", Jurnal Sains Dan Informatika, 2016, Vol.2 No.1. 